\title{
$\sqrt{ }$ \\ Disorders of visual perception
}

EDITOR'S

CHOICE

\section{See Editorial Commentary,} p 1179

${ }^{1}$ Department of Old Age Psychiatry, Institute of Psychiatry, King's College London, London, UK

${ }^{2}$ Natbrainlab, Department of Forensic and

Neurodevelopmental Sciences, Institute of Psychiatry, King's College London, London, UK ${ }^{3}$ Parnassia Bavo Group, The Hague, The Netherlands ${ }^{4}$ Department of Psychiatry, University of Groningen, Groningen, The Netherlands

\section{Correspondence to}

Dr Dominic H ffytche Department of Old Age Psychiatry, Institute of Psychiatry P070, King's College London, De Crespigny Park, London SE5 8AF, UK d.ffytche@iop.kcl.ac.uk

Received 13 November 2009 Revised 27 July 2010 Accepted 27 July 2010

\author{
Dominic H ffytche, ${ }^{1,2}$ J D Blom, ${ }^{3,4}$ M Catani ${ }^{2}$
}

\section{ABSTRACT}

Visual perceptual disorders are often presented as a disparate group of neurological deficits with little consideration given to the wide range of visual symptoms found in psychiatric and neurodevelopmental disease. Here, the authors attempt a functional anatomical classification of all disorders linked to visual perception, whatever the clinical context in which they arise, including those disorders that bridge vision, emotion, memory, language and action. Guided by clinical and neuroimaging evidence, visual perceptual disorders are classified by the functional anatomical networks likely to be involved and the class of underlying dysfunction, whether topological (a localised deficit or region of hyperfunction) or hodological (a disconnection or hyperconnection). The wider perspective forces us to consider what visual functions underlie a range of symptoms sidelined by previous classificatory schemes and helps generate novel hypotheses for further research in the area.

\section{INTRODUCTION}

If visual perception is the day-to-day experience of 'seeing'-or put another way, the conscious, visual experience of the world we have when we open our eyes-a visual perceptual disorder might be considered a deviation from this experience. Current classificatory schemes focus on disorders traditionally considered neurological (ie, based on static visual deficits typically related to brain lesions), relating each disorder to a specific brain region or its connections. ${ }^{12}$ Visual symptoms more likely to be found in psychiatric or neurodevelopmental disorders such as visual hallucinations, illusions and visual perceptual distortions, are typically only mentioned in passing or not at all in such schemes. This omission is understandable given that these types of symptoms are often transient and thus difficult to study directly, and may occur without an obvious associated brain lesion. Here we attempt to incorporate both 'neurological' and 'psychiatric' disorders into a single classificatory scheme using an anatomical network approach. Our aim is to provide an anatomically structured overview of visual perceptual dysfunction across all clinical contexts that we hope will provoke further research.

\section{A note on terminology}

The scope of our classification is set by the way we have interpreted the three constituent terms of 'visual perceptual disorder.'

\section{Visual}

The disorders classified here are visual in the sense that they are selective for vision without equivalent changes in other sensory modalities. For example, visual hypoemotionality (a loss of emotional tone for visual stimuli) implies that, in some cases at least, emotions may be preserved for auditory and other sensory stimuli.

\section{Perceptual}

In deviating from normal 'seeing', any cause of visual impairment meets the definition of a 'visual perceptual disorder' outlined above, for example, a blurring of vision through loss of acuity. To limit the scope of the review, we have focused on symptoms attributable to dysfunction within cortico-cortical or cortico-subcortical networks including those that bridge visual perception with memory, attention, emotion and action. We make a distinction between visual perception and visual imagery, as the two differ in terms of their underlying neurobiology. ${ }^{3}$ Visual percepts are seen in the external world and are outside volitional control (one cannot change the percept by force of will), whereas visual imagery is seen in the mind's eye and is under volitional control. We consider visual hallucinations and illusions as varieties of visual perceptual experience, as they are closely related to visual perception in terms of underlying brain activity. $^{3}$ Phenomena with elements of both perception and imagery are more difficult to classify. For example, experiences referred to as pseudohallucinations or incomplete hallucinations (see Blom $^{4}$ for other uses of these terms) are seen in the mind's eye but are outside volitional control. We have highlighted such ambiguous experiences in the classification and, where appropriate, presented both perceptual and imagery viewpoints.

\section{Disorder}

We use the term disorder for continuity with previous clinical literature, although much of the classification relates to perceptual symptoms that do not imply a specific disease or pathology.

\section{Hodotopic framework}

We have classified visual perceptual disorders using the general anatomical framework we set out in 2005 as an update of classical associationist and neo-associationist accounts of higher cognitive function and dysfunction..$^{5}$ Recent advances in functional neuroanatomy, using techniques such as functional MRI (fMRI) and diffusion tensor tractography (DT-tractography), provide complementary views of the anatomy of higher function and the pathological mechanisms that generate cognitive and behavioural symptoms. One view, termed topological (from 'topos'=place), relates higher function and dysfunction to discrete cortical locations. The other, termed hodological (from 'hodos'=path), relates higher function and dysfunction to connections between locations. Both 
views are combined in a generic neuroanatomical model applicable to all higher functions and dysfunctions - the hodotopic framework. ${ }^{5}$ From the perspective of the hodotopic framework, each higher function relates to a specific network of cortical locations and white-matter connections. Topological disorders are localised within a cortical area and result in a loss (deficit) or an increase in function (hyperfunction). Hodological disorders relate to connections between areas, including those in which function in one brain region is altered by changes in another, spatially remote, region. We use von Monakow's term 'diaschisis' to refer to such remote effects ${ }^{6}$; however, the term is not intended here to carry its original implication of transient neurological shock. Connections between areas can be decreased (disconnection) or increased (hyperconnection) in hodological disorders. Deficit and disconnection disorders of visual perception are found in stroke, intracranial compressing masses, neurosurgical procedures, demyelinating disorders, neurodevelopmental conditions (eg, autism), neurodegenerative disease, schizophrenia and depression. Hyperfunction and hyperconnection disorders of visual perception are found in ophthalmic disease, neurodegenerative disease, Parkinson's disease, psychosis, epilepsy and as normal phenomena in relation to sleep or in the context of psychedelic drugs, alcohol or medication side-effects.

\section{Classification method}

We have allocated each visual perceptual symptom to a visual network and one of four classes of dysfunction (topological versus hodological; hyper- versus hypo-function/connection). For some symptoms, functional imaging, DT-tractography or lesion evidence is available to help identify the appropriate location in the table (eg, a localised increase in activity within a specific brain region or a decrease in connectivity within a specific tract). However, for many, we have been forced to make an educated guess through: (1) analogies to related symptoms for which evidence is available and (2) a neurophenomenological approach. ${ }^{3} 7$ This approach is derived from the body of research into the neural correlates of consciousness (NCC) which suggests that some, as yet undefined, aspect of activity within a specialised cortical region (resulting in an increase in imaging signal ${ }^{8}$ ) contributes directly to visual perceptual experience (eg, the percept of a face is associated with increased activity within face-specialised cortex ${ }^{9}$ ). Where evidence is available, this principle seems also to apply to hallucinatory, illusory and synaesthetic percepts. ${ }^{3}$ Thus, the content of visual perceptual experience (whether an object, a face, motion, etc) localises activity to a particular brain region or network, irrespective of whether the experience is a normal percept, illusion, hallucination, etc.

\section{A taxonomy of disordered visual perception}

Table 1 and figure 1 outline a tentative classification of visual perceptual disorders.

\section{Topological disorders of visual perception Deficits}

Prototypical disorders of this nature are characterised by the selective loss of a specific visual perceptual function-for example, achromatopsia ${ }^{14}$ (selective loss of colour vision following lesions of colour-specialised cortex) and akinetopsia ${ }^{15}$ (selective loss of motion vision following lesions of lateral occipital motion-specialised cortex; the motion deficit is not absolute with a relative sparing of the perception of slow movement ${ }^{16}$ ).
Lesions of V1 result in a scotoma restricted to a single hemifield (a hemianopia if the lesion involves the entire extent of V1 in one hemisphere). Lesions of ventral V2/V3 (within subcalcarine BA18) are associated with upper quadrantic field defects, while those of dorsal V2/V3 (supracalcarine BA18) are associated with inferior quadrantic field detects. ${ }^{17}$ Scotomata in the context of migraine aura relate to regions of cortical spreading depression-like activity in early visual areas (eg, V1, V2 and $\left.\mathrm{V}^{18}\right)$.

Face perception deficits (the prosopagnosias) have a variety of subtypes likely to reflect the involvement of different functional modules within the face-processing system, although disconnection mechanisms may also be involved. ${ }^{19}$

An inability to recognise familiar places (environmental agnosia) is associated with medial temporal lobe lesions ${ }^{20}$ and can be considered a topological deficit of cortex specialised for the visual environment (parahippocampal place area ${ }^{21}$ ) or a hodological disconnection of visual and memory representations of places ${ }^{20}$ within the hippocampal-retrosplenial network (ventral cingulum).

Size and object distortions are referred to collectively as metamorphopsias. Objects appearing larger or smaller (macropsia and micropsia respectively) have been attributed to a dysfunction of object constancy within the temporal lobe (the integration of object distance with retinal visual angle to estimate size), although it is unclear whether this is best conceived as a topological dysfunction (ie, a deficit or hyperfunction of a cortical region specialised for constancy) or a hodological dysfunction (ie, a disconnection or hyperconnection of relevant specialised modules). The same mechanism may be responsible for objects appearing nearer or further away (pelopsia and teleopsia respectively), although such symptoms can also be interpreted as disorders of depth perception (and are also referred to as enhanced stereopsis ${ }^{4}$ ). Lesions of lateral occipito-temporal cortex may cause micropsia in one hemifield ${ }^{22}$ or bilaterally, ${ }^{23}$ although as object constancy may be preserved, ${ }^{23}$ such cases may relate to a deficit of object processing rather than constancy.

Apperceptive agnosia and cortical blindness describe diffuse visual loss affecting many visual domains. They occur in the context of extensive occipital lesions and are likely to involve both topological and hodological dysfunction. Several subtypes of disordered form perception have been described, ${ }^{24}$ each likely to depend on the form perception submodule(s) involved in the lesion. Scieropia refers to darkening of vision and follows diffuse occipital damage (see Wapner et al ${ }^{25}$ for an example: a patient whose vision was dimmed as if seeing everything at twilight). The same symptom occurring without other visual impairments (scierneuropsia) was described in the psychoanalytic literature ${ }^{26}$ and is likely to be an example of derealisation (see below).

The Riddoch syndrome is a variant of cortical blindness in which motion-specialised cortex (V5) remains intact and is activated through direct connections from the LGN and/or pulvinar. $^{11}$ Subjects are able to consciously perceive and discriminate visual motion in their otherwise blind visual field when stimulated with fast motion, ${ }^{11}$ while under other stimulus conditions report visual percepts without the ability to discriminate (gnosanopsia) or have intact discrimination ability without visual percepts (blindsight or agnosopsia). ${ }^{11}$

In visuo-spatial neglect, patients have a deficiency of orienting attention to one hemifield (usually left) and (may) fail to perceive stimuli in this region when rival stimuli are present in the non-neglected hemifield (extinction). The disorder has been interpreted as topological (related to the cortical modules involved 
Table 1 Disorders of visual perception

\begin{tabular}{|c|c|c|c|c|c|c|}
\hline & \multicolumn{3}{|l|}{ Topological } & \multicolumn{3}{|l|}{ Hodological } \\
\hline & Cortex & Hyperfunction & Deficit & White matter & Hypoconnection & Hyperconnection \\
\hline Subcortical/Brainstem & & Phosphenes & $\begin{array}{l}\text { Brainstem/subcortical } \\
\text { visual deficits }\end{array}$ & $\begin{array}{l}\text { Subcortical } \\
\text { pathways }\end{array}$ & $\begin{array}{l}\text { Charles Bonnet syndrome } \\
\text { Peduncular hallucinosis }\end{array}$ & Dazzle \\
\hline V1/V2/V3 & $\mathrm{BA} 17 / 18$ & $\begin{array}{l}\text { Phosphenes/ } \\
\text { Simple hallucinations } \\
\text { Visual snow } \\
\text { Teichopsia }\end{array}$ & $\begin{array}{l}\text { Cortical blindness* } \\
\text { Scotoma } \\
\text { Apperceptive agnosia* } \\
\text { Scieropia* } \\
\text { Riddoch syndrome }\end{array}$ & U-shaped & $\begin{array}{l}\text { Cortical blindness* } \\
\text { Apperceptive agnosia* } \\
\text { Scieropia* }\end{array}$ & \\
\hline Depth (stereopsis) & & & & Splenium & Astereopsis (split brain) & \\
\hline \multicolumn{7}{|l|}{ Ventral Stream } \\
\hline Colour & BA18/19 & $\begin{array}{l}\text { Colour hallucination/illusion/ } \\
\text { hyperchromatopsia }\end{array}$ & Achromatopsia & $\begin{array}{l}\text { ILF/Arcuate } \\
\text { U-shaped }\end{array}$ & Colour anomia* & $\begin{array}{l}\text { Coloured hearing, } \\
\text { coloured } \\
\text { music, coloured } \\
\text { grapheme } \\
\text { synaesthesia }\end{array}$ \\
\hline Face gestalt & BA37 & $\begin{array}{l}\text { Face hallucination/illusion } \\
\text { Facial intermetamorphosis* }\end{array}$ & Prosopagnosia* & ILF/IFOF & Prosopagnosia* & Pareidolia for faces \\
\hline Face feature & BA19 & Prosopometamorphopsia & Prosopagnosia* & ILF/IFOF & Prosopagnosia* & \\
\hline Object & BA18/19/37 & $\begin{array}{l}\text { Object hallucination/illusion } \\
\text { Lilliputian hallucinations }\end{array}$ & $\begin{array}{l}\text { Object agnosia* } \\
\text { /Micropsia }\end{array}$ & ILF/IFOF/Arcuate & $\begin{array}{l}\text { Object agnosia* } \\
\text { Object anomia } \\
\text { Optic aphasia }\end{array}$ & Pareidolia for objects \\
\hline Places & $\begin{array}{l}\text { Parahippocampal } \\
\text { gyrus }\end{array}$ & Landscape hallucinations & $\begin{array}{l}\text { Environmental } \\
\text { agnosia* }^{*}\end{array}$ & & & \\
\hline Constancy & & $\begin{array}{l}\text { Micropsia/macropsia* } \\
\text { Pelopsia/telopsia* }\end{array}$ & $\begin{array}{l}\text { Micropsia/Macropsia* } \\
\text { Pelopsia/telopsia* }\end{array}$ & & $\begin{array}{l}\text { Micropsia/macropsia* } \\
\text { Pelopsia/telopsia* }\end{array}$ & $\begin{array}{l}\text { Micropsia/macropsia* } \\
\text { Pelopsia/telopsia* }\end{array}$ \\
\hline Text & BA37 & Visual text hallucination & Alexia* & $\begin{array}{l}\text { ILF/Splenium/ } \\
\text { U-shaped }\end{array}$ & $\begin{array}{l}\text { Alexia* } \\
\text { Left hemialexia (split brain) }\end{array}$ & $\begin{array}{l}\text { Coloured grapheme } \\
\text { synaesthesia }\end{array}$ \\
\hline Text Semantics & BA20/21/38 & $\begin{array}{l}\text { Visual command } \\
\text { hallucination }\end{array}$ & Surface dyslexia* & ILF/IFOF & Surface dyslexia* & \\
\hline \multicolumn{7}{|l|}{ Dorsal Stream } \\
\hline Motion vision & BA19/37 & $\begin{array}{l}\text { Motion hallucination/illusion } \\
\text { Passage hallucination }\end{array}$ & Akinetopsia & U-shaped & Cinematographic vision & \\
\hline $\begin{array}{l}\text { Spatial } \\
\text { co-ordinate frames }\end{array}$ & $\mathrm{BA} 7 / 31$ & $\begin{array}{l}\text { Polyopia /Entomopia } \\
\text { Visual perseveration } \\
\text { Trailing phenomenon } \\
\text { Delayed palinopsia } \\
\text { Illusory visual spread } \\
\text { Positive afterimages }\end{array}$ & & U-shaped & & Number forms \\
\hline Depth (reaching) & $\mathrm{BA} 7 / 19 / 39$ & & Optic ataxia* & $\begin{array}{l}\text { U-shaped } \\
\text { Splenium }\end{array}$ & $\begin{array}{l}\text { Optic ataxia* } \\
\text { Crossed optic ataxia } \\
\text { (split brain) }\end{array}$ & \\
\hline \multicolumn{7}{|l|}{ Visual attention } \\
\hline & $\mathrm{BA} 6 / 7 / 8 / 39 / 40$ & & $\begin{array}{l}\text { Visuo-spatial neglect* } \\
\text { Extinction* } \\
\text { Visual fading* } \\
\text { Simultanagnosia* } \\
\text { Inverse Anton's* } \\
\text { Negative hallucination* }\end{array}$ & $\begin{array}{l}\text { SLF/Cingulum/ } \\
\text { U-shaped }\end{array}$ & $\begin{array}{l}\text { Visuo-spatial neglect* } \\
\text { Extinction* } \\
\text { Visual fading* } \\
\text { Simultanagnosia* } \\
\text { Inverse Anton's* } \\
\text { Negative hallucination* }\end{array}$ & \\
\hline & $\mathrm{BA} 6 / 7$ & & Oculomotor apraxia* & SLF & Oculomotor apraxia* & \\
\hline $\begin{array}{l}\text { Awareness of body } \\
\text { schema }\end{array}$ & & & & U-shaped & $\begin{array}{l}\text { Anton's syndrome } \\
\text { (anosognosia) }\end{array}$ & \\
\hline \multicolumn{7}{|l|}{ Visual memory } \\
\hline Imagery & $\begin{array}{l}\text { Hippocampus/ } \\
\text { Parahippocampal } \\
\text { gyrus/ } \\
\text { BA11/47/45 }\end{array}$ & $\begin{array}{l}\text { Anton's syndrome } \\
\text { (confabulation) } \\
\text { PTSD flashbacks* } \\
\text { Flashbulb memories } \\
\text { Memory hallucination } \\
\text { Re-perceptive hallucination* }\end{array}$ & $\begin{array}{l}\text { Visual imagery deficits* } \\
\text { Visual anoneria** }\end{array}$ & ILF/IFOF & $\begin{array}{l}\text { Visual imagery deficits* } \\
\text { Visual anoneria* } \\
\text { Visual amnesia }\end{array}$ & $\begin{array}{l}\text { Perky effect } \\
\text { PTSD flashbacks* } \\
\text { Eidetic imagery } \\
\text { Re-perceptive } \\
\text { hallucination* }\end{array}$ \\
\hline Faces & & & & ILF/IFOF & Capgras syndrome & Frégoli's phenomenon \\
\hline Places & & & & ILF/IFOF & $\begin{array}{l}\text { Reduplication of places } \\
\text { Environmental agnosia* }\end{array}$ & \\
\hline \multicolumn{7}{|l|}{ Visual emotion } \\
\hline & $\begin{array}{l}\text { Amygdala / } \\
\text { BA11/47/45 }\end{array}$ & $\begin{array}{l}\text { Phobic disorders* } \\
\text { PTSD flashbacks* } \\
\text { Flashbulb memories }\end{array}$ & $\begin{array}{l}\text { Fear recognition } \\
\text { deficits }\end{array}$ & ILF/IFOF & $\begin{array}{l}\text { Visual hypo-emotionality } \\
\text { De-realisation }\end{array}$ & $\begin{array}{l}\text { Phobic disorders* } \\
\text { PTSD flashbacks* } \\
\text { Kakopsia/Kalopsia }\end{array}$ \\
\hline Faces & & & & ILF/IFOF & Capgras syndrome & Frégoli's phenomenon \\
\hline Places & & & & ILF/IFOF & Reduplication of places & \\
\hline
\end{tabular}


Table 1 Continued

\begin{tabular}{|c|c|c|c|c|c|c|}
\hline & \multicolumn{3}{|l|}{ Topological } & \multicolumn{3}{|l|}{ Hodological } \\
\hline & Cortex & Hyperfunction & Deficit & White matter & Hypoconnection & Hyperconnection \\
\hline \multicolumn{7}{|c|}{ Visual vestibular } \\
\hline & BA22/39/40 & $\begin{array}{l}\text { Autoscopy/Heautoscopy/ } \\
\text { OBE* } \\
\text { Extracampine hallucinations* } \\
\text { Oculogravic illusion* } \\
\text { Oculogyral illusion* } \\
\text { Caloric visual hallucinations* } \\
\text { Zingerle's automatosis* } \\
\text { PPA* }^{*}\end{array}$ & $\begin{array}{l}\text { Visual alloaesthesia/ } \\
\text { Inverted vision* }\end{array}$ & U-shaped/Arcuate & $\begin{array}{l}\text { Visual alloaesthesia/ } \\
\text { Inverted vision* }\end{array}$ & $\begin{array}{l}\text { Autoscopy/Heautoscopy/ } \\
\text { OBE* } \\
\text { Extracampine } \\
\text { hallucinations* } \\
\text { Oculogravic illusion* } \\
\text { Oculogyral illusion* } \\
\text { Caloric visual } \\
\text { hallucinations* } \\
\text { Zingerle's automatosis* } \\
\text { PPA* }^{*}\end{array}$ \\
\hline Visual axis & BA40/39/insula & & $\begin{array}{l}\text { Axis impairment } \\
\text { Environmental tilt* }\end{array}$ & $\begin{array}{l}\text { U-shaped/ } \\
\text { Arcuate }\end{array}$ & $\begin{array}{l}\text { Axis impairment } \\
\text { Environmental tilt* }\end{array}$ & \\
\hline \multicolumn{7}{|l|}{ Visual motor } \\
\hline Limb Praxis & & & & $\begin{array}{l}\text { SLF } \\
\text { SLF/Arcuate }\end{array}$ & $\begin{array}{l}\text { Utilisation behaviour } \\
\text { Visual imitative apraxia }\end{array}$ & \\
\hline
\end{tabular}

*Disorders likely to relate to both hodological and topological dysfunction.

BA, Brodmann area; PPA, paroxysmal perceptual alteration; PTSD, post-traumatic stress disorder.

in visuospatial processing and attention-see Mort et $a l^{27}$ for a review of regions implicated) but hodological mechanisms have also been suggested. ${ }^{28}$ Simultanagnosia (an inability to sustain attention across different locations in the visual field) leads to objects appearing fragmented or disappearing from view ${ }^{29}$ with shrinkage of the visual attentional field. ${ }^{30}$ The disorder is likely to relate to parietal lobe specialisations for spatial visual attention, although it is unclear whether the disorder is best conceived as topological or hodological. Rapid fading of vision found with occipito-parietal lesions ${ }^{31}$ is likely to be caused by the same mechanism as simultanagnosia.

Selective lesions of the amygdala are associated with perceptual deficits of emotional facial expression ${ }^{32}$ with similar deficits described in autism spectrum disorder and psychopathy.

Visual imagery may be selectively impaired (ie, with intact auditory, olfactory, gustatory, etc imagery; see Basso et al ${ }^{33}$ for a review of case reports) with a relative preservation of visual perception. Loss of visual imagery may also be accompanied by a specific loss of visual dreaming (visual anoneria ${ }^{34}$ ) or a more general loss of dreams in all sensory modalities (CharcotWilbrand syndrome ${ }^{35}$ ). Such disorders can be interpreted as topological deficits of visual imagery generation or hodological disconnections within visual memory networks.

\section{Hyperfunction}

Topological disorders of hyperfunction are related to pathophysiological mechanisms such as local irritation (eg, in epilepsy or at the margins of a cortical lesion) and deafferentation caused by eye disease (Charles Bonnet Syndrome) or a visual pathway lesion; the mechanism by which loss of visual input results in increased cortical activity is unclear but may relate to changes in thalamocortical circuitry. ${ }^{36}$

Hallucinations linked to V1 and surrounding areas (V2/V3) are of simple featureless forms, colours and television-like static (visual snow). These phenomena are termed phosphenes or photopsias by some authors, although they are perhaps better referred to as simple hallucinations, given that they differ from other types of visual hallucination only in the location of cortex involved. $^{36}$ In migraine aura, zigzag lines and patterns (teichopsia ${ }^{37}$ ) relate to the margins of a region of cortical spreading depression-like activity in early visual cortex. ${ }^{18}$

Colour, object and landscape hallucinations are each linked to their respective region of cortical specialisation, ${ }^{36} 3839$ and the same is likely to be the case for motion hallucinations and passage hallucinations (visual hallucinations of persons or animals that pass sideways out of the visual field). Increased vividness of an attribute (eg, increased vividness of colours: hyperchromatopsia ${ }^{40}$ ) is thought to relate to increased activity within the relevant specialised region (eg, colour-specialised cortex for hyperchromatopsia). The origin of lilliputian hallucinations (small figures, often in costume) is unclear but has been classified here as related to object specialisations. The reduced size of such hallucinations may relate to visual constancy mechanisms. ${ }^{40}$

Text or letter-string hallucinations lacking semantic content are linked to the cortical area specialised for word forms, while those with semantic content (visual command hallucinations and visual verbal hallucinations ${ }^{4}$ ) are linked to higher-level representations of visual language. ${ }^{41}$

Illusions of distorted faces (prosopometamorphopsia) relate to activity on the lateral convexity of the occipital lobe, ${ }^{42}$ a region specialised for face features (the occipital face area), and the same region is likely to account for hallucinations of distorted faces. Hallucinations of normal (undistorted) faces relate to activity within ventral occipito-temporal cortex (fusiform face area), ${ }^{38}$ and the same region is likely to account for facial intermetamorphosis (a change in the visually perceived identity of a face).

A range of symptoms collectively termed palinopsia ${ }^{40} 43$ have been linked to dysfunction within parietal-lobe coordinate systems. ${ }^{44}$ They include: (1) polyopia (perceiving multiple copies of the same object often arranged in rows and columns; if the number of copies is large (eg, >100) it is referred to as entomopia ${ }^{45}$ ); (2) visual perseveration (an object remaining fixed in retinal coordinates with eye movements); (3) delayed palinopsia (an object returning to field of view); and (4) illusory visual spread (the spread of a pattern from an object to its surroundings). Parietal lobe regions are also likely to underlie the trailing phenomenon (a variety of visual perseveration in which a series of discontinuous stationary images trail behind a moving object) and positive afterimages (afterimages in which objects are seen in their true as opposed to complementary colours).

Patients with Anton's syndrome (visual anosognosia/denial of blindness in the context of cortical blindness) report visual experiences that are traditionally interpreted as confabulations (false memories or false reports of visual perceptual experience) or visual imagery experiences. ${ }^{46}$ These symptoms are likely to be the result of topological hyperfunction within visual memory systems. Flashbulb memories (detail-perfect memories of events 
Figure 1 Anatomy of visual networks. The upper left panel shows the major associative tracts with connection to the occipital lobe in the human brain. The Brodmann areas corresponding to the cortical projections of each fibre tract are given in the lower left panel. The right panels show Brodmann areas colour-coded on lateral (upper) and medial (lower) views of the brain. Images modified from Catani and Thiebaut de Schotten. ${ }^{10}$ The primary visual cortex (V1, area 17) is located on the polar and medial surface of the occipital lobe. V2 (within BA18) is adjacent to $\mathrm{V} 1$ and is divided on the medial occipital surface into a dorsal portion and a ventral portion. V3 (within BA18) is adjacent to V2 and is similarly divided. The occipital lobe, lateral and ventral occipitotemporal cortex, limbic cortex and the parietal lobe contain regions specialised for different visual

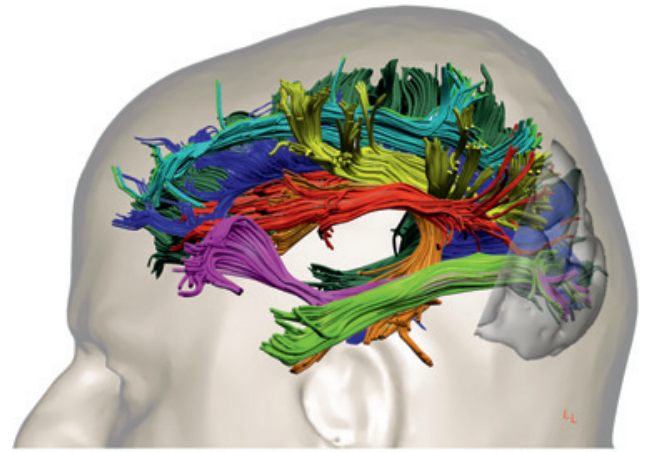

Arcuate (BA42,21, 22,37,6,44) SLF II $(B A 6,39,40)$

SLF I (BA6,7,8,9)

SLF III (BA39,40, 6,44)

Corpus callosum

IFOF (BA18, 19, 37, 11, 47)

ILF (ventral BA18,19,20,21,37, 38, amygdala, hippocampus)

Cingulum (BA6, 7,8,24,26,31,32,33,34)
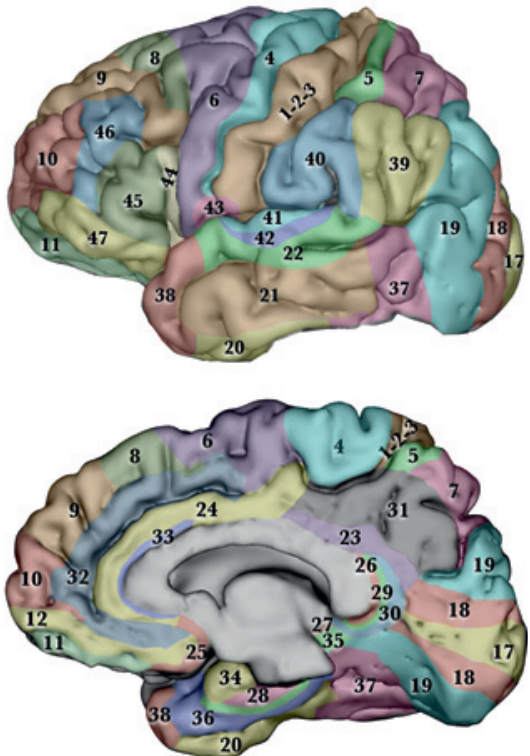
perceptual attributes, including: familiar faces, colours, extended landscapes, objects, text and visual textures (ventral occipito-temporal cortex) and visual motion, body parts, face features, intermediate-level object processing, and eye and mouth movements (posterior-lateral cortex). ${ }^{7}$ The predominant pathway from the eye to V1 relays through the lateral geniculate nucleus (LGN), although a clinically important pathway passes directly from the LGN or pulvinar to motion-specialised cortex (V5 within BA 19/37) on the lateral occipital surface. ${ }^{11}$ The detailed anatomy of fibres within and between occipital regions and from the occipital lobe to the pulvinar has yet to be characterised in man. Chains of U-shaped fibres and parallel long association pathways passing to the parietal lobe form a cortical network (dorsal stream) ${ }^{12}$ thought to underlie spatial aspects of vision, while equivalent pathways to the temporal lobe form a cortical network (ventral stream) thought to underlie object vision, colours, faces and visual language. The inferior longitudinal fasciculus (ILF) carries reciprocal connections between the occipital and medial/lateral anterior temporal lobes related to visual emotion and visual memory. ${ }^{13}$ The inferior fronto-occipital fasciculus (IFOF) connects territories in the occipital lobe and ventral frontal lobe. ${ }^{12}$ Connections between the visual parietal lobe and frontal cortex are carried in the superior longitudinal fasciculus (SLF), while those between occipital and limbic cortex are carried in the cingulum and ILF. The SLF and IFOF are likely to relate to functions such as visual attention, visual working memory, visual praxis, visual-vestibular function and eye movement control. Cortico-cortical visual connections between hemispheres pass predominantly through the splenium of the corpus callosum.

that at the time of witnessing evoked a high level of surprise, consequentiality and/or emotional arousal ${ }^{47}$ ) and memory hallucinations (fantastic false memories conjured up retrospectively ${ }^{4}$ ) may relate to a similar hyperfunction of visual memory systems (and/or visual emotion systems in the case of flashbulb memories). Reperceptive hallucinations involve the replay of memory fragments (also termed experiential hallucinations ${ }^{4}$ ); however, it is unclear whether such experiences are visual imagery or visual percepts. ${ }^{48}$ If visual imagery, they are likely to involve hyperfunction of memory systems; if visual percepts, they are likely to involve hyperconnection between visual memory networks and occipital cortex.

Autoscopic phenomena describe a range of experiences in which the self is duplicated in external space. In autoscopy, the duplicate self is seen in the external world. In an out-of-body experience $(\mathrm{OBE})$ the physical body is seen from the perspective of the duplicated external self. In heautoscopy the hallucinated 'double' is identified as oneself, despite the lack of an exact physical resemblance, and the subjective viewpoint may change between the double and physical self in rapid alternation. These phenomena are thought to relate to the disintegration of visual, proprioceptive, tactile and vestibular modalities, and have been linked to transient dysfunction in the region of the temporoparietal junction (TPJ). ${ }^{49}$ Whether this dysfunction is better conceived as topological hyperfunction of one or more of the sensory modalities involved or a hodological connectivity increase between specialised regions is unclear. Visual extracampine hallucinations (hallucinations perceived in impossible locations outside the field of view) could be considered related phenomena in that they involve an alteration in the reconstruction of visual space and body schema. Other disorders likely to be related to hyperfunction or hyperconnection within the TPJ and related regions include: (1) the oculogravic illusion (an illusory displacement of objects co-occurring with a change in gravity as in a diving airplane ${ }^{50}$ ); (2) the oculogyral illusion (the apparent movement of a stationary light in a dark room during fixation following a period of rotation ${ }^{50}$ ); (3) visual hallucinations occurring in association with caloric stimulation ${ }^{51}$; (4) Zingerle's automatosis in which visual hallucinations occur during transient motor and vestibular dysfunction ${ }^{3}$ (eg, compulsive posturing, torticollis, choreo-athetosis); (5) the transient intensification of visual patterns and text, often in association with neuroleptic induced oculogyric crises (paroxysmal perceptual alteration ${ }^{52}$ ).

\section{Hodological disorders of visual perception \\ Disconnection}

Disconnection of cortical visual networks from subcortical inputs as a result of visual pathway lesions or eye disease is associated with simple and complex visual hallucinations and visual illusions ${ }^{37}$ (the Charles Bonnet Syndrome-the change in cortical function secondary to eye disease might be considered a form of diaschisis). Brainstem lesions are associated with peduncular hallucinations (complex hallucinations associated with eye movement disorders and changes in arousal or sleep ${ }^{53}$ ).

Depth vision (visual space) involves a number of dissociable $e^{54}$ functions, some related to perceptual aspects of depth (eg, stereopsis (binocular vision) and object constancy), others related to action aspects of depth (eg, reaching behaviour). One aspect of depth vision (stereopsis) is lost in the central visual field (but not the visual periphery) following splenial section. ${ }^{55}$ 
In cinematographic vision, moving objects appear as a series of static freeze frames at different spatial locations. ${ }^{4}$ The disorder may relate to the disconnection of motion specialised cortex and spatial coordinate frames in the parietal lobe.

Associative object agnosia (loss of object meaning with intact object perception) is thought to relate to the disconnection of visual and semantic regions (see Riddoch and Humphreys ${ }^{24}$ for a review). Specific deficits of colour or object naming (colour anomia, object anomia) are thought to relate to the disconnection of visual and language areas, while optic aphasia (an inability to name objects by sight with preserved ability to name by touch or from description) is thought to follow disconnection of left-hemisphere verbal semantic and right-hemisphere visual semantic representations. ${ }^{56}$

Pure alexia (a deficit of reading words with preserved writing and letter recognition) and left hemialexia (a reading deficit restricted to the left hemifield) have been interpreted as hodological dysfunctions (a disconnection of a left-hemisphere region specialised for word forms from visual inputs) and topological dysfunctions (a deficit of the word form area) (see Epelbaum et $a l^{57}$ for a review). In surface dyslexia, the link between word forms and semantics is impaired so that reading occurs through phonology with characteristic errors for irregular words. ${ }^{58}$ The disorder might be considered a disconnection of regions specialised for word forms from regions specialised for visual semantics or a topological deficit of visual semantic specialisations.

The action aspect of depth vision (reaching behaviour) is dysfunctional in optic ataxia (impaired reaching with intact motor and visual function) and is thought to reflect an inability to integrate different coordinate frames within the parietal lobe. ${ }^{59}$ The failure of integration might reflect a hodological disconnection of the relevant reference frames or a topological deficit of an area specialised for their integration. A variant (crossed optic ataxia) in which reaching into contra-lateral hemispace is impaired (eg, reaching with the right hand for an object located on the left side) is thought to relate to the disconnection of the two hemispheres with a combination of splenial and parietal lesions. ${ }^{60}$

Oculomotor apraxia (a disorder of gaze in which subjects are unable to move gaze voluntarily from one object to another with preserved reflex gaze shifts) can be interpreted as a disconnection of voluntary saccadic systems in the frontal lobe from reflex saccadic systems in the parietal lobe (a network classified here as related to visual attention).

Denial of cortical blindness (Anton syndrome) might be considered a disconnection of visual cortex from body schema representations in the parietal lobe (classified here as related to visual attention). An inverse Anton syndrome (denial of seeing) has been interpreted as a disconnection of parietal attentional mechanisms and visual cortex. ${ }^{61}$ Denial of seeing specific objects reported in hypnosis (termed negative hallucination or scotomisation ${ }^{4}$ ) is likely to relate to the same mechanism.

In reduplicative disorders, a familiar person, place or object is perceived as replaced by a duplicate person, place or object ${ }^{62}$ (termed Capgras syndrome when involving a person). Reduplicative phenomena are thought to relate to the disconnection of visual and affective or memory regions. ${ }^{63}$ Similar disconnection accounts are given for derealisation (the feeling that experiences, typically visual, seem strange or unreal), visual hypoemotionality (where visual experience lacks emotional tone) ${ }^{64}$ and visual amnesia (a deficit of registering visual experiences in short-term memory). ${ }^{65}$

Visual alloaesthesia involves the transposition, rotation, tilting or inversion of the visual field (also referred to as reversal of vision metamorphopsia ${ }^{66}$ ) and has variants where the visual environment (but not the visual field) is rotated. ${ }^{2}$ The mechanism behind these disturbances is unclear but may relate to a disconnection of vestibular and visual inputs, transcallosal disconnection of visual and parietal inputs or topological lesions affecting regions specialised for the integration of these modalities. $^{2}$ The disorders are associated with occipito-parietal lesions that spare the optic radiations and with brainstem pathology. ${ }^{66}$ Deficits of visual axis perception (eg, judgement of true vertical or horizontal) are associated with lesions of the anterior parietal lobe and have been attributed to a disconnection of vestibular inputs and their cortical representation or topological deficits of vestibular representations in the parietal lobe. ${ }^{67}$

The inability to mimic meaningless or meaningful actions or postures (visual imitative apraxia) is likely to reflect disconnection of visual and motor representations. ${ }^{68}$ Utilisation behaviour (automatic manual exploration and use of objects placed within the field of view and reach) has been interpreted as a deficit of frontal inhibitory function on parietal-led exploratory behaviour ${ }^{69}$ and might be considered a form of diaschisis. Automatic exploration of objects by placing them in the mouth forms part of the Klüver-Bucy syndrome (also including visual agnosia and hypersexuality) following anterior temporal lobe lesions.

\section{Hyperconnection}

Of the four classes of dysfunction, hodological hyperconnection is the most speculative; however, there is indirect evidence that connectivity increases are linked to perceptual symptoms in the auditory domain. $^{70}$ Increased connectivity might lead to perceptual symptoms through, for example, enhanced feedforward or feedback processing or resonant activation through ephaptic (non-synaptic) transmission. The prototypical disorder in this class is synaesthesia. In the clinical domain, synaesthesia has traditionally referred to a percept in one sense modality evoking a parallel hallucinatory percept in a different sense modality-for example, percepts of taste evoking visual percepts of colour (coloured taste synaesthesia). More recently, work in the cognitive sciences has lifted the requirement of synaesthetic experience to cross modalities through the study of, for example, coloured grapheme synaesthesia (visual percepts of text evoking visual percepts of colours). The induced synaesthetic experience may be perceived in the external world (projector synaesthesia) or inside the mind's eye (associator synaesthesia). ${ }^{71}$ Other parallel sensory experiences recognised clinically include reflex hallucinations (a sensory stimulus in one modality evokes a hallucination in another, eg, seeing a butterfly whenever the thumb is touched) and functional hallucinations (hallucinations are triggered in the same modality as the inducing stimulus, eg, hearing voices in parallel with the sound of running water). Both clinical symptoms would be classed as synaesthetic by contemporary cognitive science. We would argue that the content of the parallel experience in such disorders is defined by the cortical specialisation of the area with increased connectivity. Thus, for example, synaesthesiae, reflex or functional hallucinations that involve colour relate to the connectivity of colour-specialised cortex, while experiences involving spatial location (ie, number forms-a variety of synaesthesia in which numbers and other ordinal lists, eg, days of the week, are located at specific spatial locations ${ }^{72}$ ) relate to the connectivity of spatial representations in the parietal lobe.

Pareidolia refers to images of objects or faces seen in random visual patterns (eg, cloud formations or tree bark). The experience is an illusion in which the inducing visual stimulus is typically of simpler form than the illusory percept and can be considered the result of hyperconnection between visual areas. 
The Frégoli syndrome, in which unfamiliar people are perceived as familiar (typically as a person in disguise with malevolent intent), can be conceived as hyperconnection within visual emotional or memory networks. In post-traumatic stress disorder flashbacks, patients relive stressful events, typically with multiple sensory modalities involved and a strong emotional component. The flashbacks might be considered the result of hodological hyperconnection between visual and emotional systems or topological hyperfunction of visual memory systems.

The Perky effect originally referred to an ambiguity between visual imagery and visual perception such that normal subjects were unable to detect the presence of a real visual stimulus when asked to form a visual image of it. More recently, the term has been used to describe the reduction in visual perceptual sensitivity during visual imagery. ${ }^{73}$ The effect is likely to relate to connectivity between visual memory networks and occipital cortex. Eidetic imagery (sometimes referred to as photographic memory $)^{74}$ is likely to relate to increased connectivity between these regions.

Visual phobias and visual objects appearing beautiful and comforting (kalopsia) or ugly and menacing (kakopsia) ${ }^{75}$ might be considered the result of hodological hyperconnection between visual emotional networks and occipital cortex or topological hyperfunction of visual specialisations within the amygdala.

Dazzle (painful brightness of visual stimuli) is thought to be a visual variant of a thalamic pain syndrome ${ }^{76}$ and can be interpreted as hodological hyperconnection of the thalamus and visual cortex. The same mechanism may account for the intense photophobia of children with cortical visual impairment and the paradoxical worsening of their visual acuity (as measured by the evoked response) for lighter (higher luminance) compared with darker (lower luminance) visual stimuli. ${ }^{77}$

\section{LIMITATIONS}

The classificatory scheme has a number of limitations and is perhaps better viewed as a structured review of symptoms from which to generate and test further experimental hypotheses than a definitive pathophysiological taxonomy or clinical aide memoire. First, it does not easily accommodate disorders involving combinations of networks or combinations of topological and hodological dysfunction (the latter marked with an asterisk in the table 1). Typical lesions have both hodological and topological effects so that pure disorders of one or other class may be largely theoretical. Second, the classification deconstructs traditional clinical syndromes by placing their component parts in different locations, losing associations between symptoms related to the anatomical proximity of the cortical regions underlying them. For example, in migraine aura, the same region of cortical spreading depression may result in a hyperfunctional symptom at its margins (teichopsia) and a deficit in its centre (a scotoma), but each is placed in a different location in the table 1. Similarly, the Balint syndrome (simultanagnosia, optic ataxia and oculomotor apraxia in association with biparietal lesions ${ }^{78}$ ) is spread across the table 1. Third, hyper- and hypofunction are convenient concepts to map on the statistical signal increases and decreases in imaging and tractography data. However, the neurophysiological meaning of such changes is unspecified. An increase in activity as measured by fMRI may have a number of neurophysiological causes (eg, a change in excitatory input or inhibitory processing, a shift from burst to tonic mode firing, ${ }^{36}$ neuromodulatory inputs, etc). Similarly DT-tractography dissects virtual connections between brain regions and different causes of microstructural whitematter change may lead to the same change in connectivity. By focussing on increases or decreases in imaging signal, the classification is likely to miss key pathophysiological distinctions. Finally, the classification does not easily accommodate interactions between predisposing factors and changes occurring at the time of a symptom. The Charles Bonnet Syndrome, for example, appears both as a hodological disconnection (because of the predisposing factor of loss of visual inputs from the eye) and as topological hyperfunction (because of the localised increases in fMRI signal during hallucinations).

\section{CLINICAL IMPLICATIONS}

Despite its limitations, the classificatory scheme and its underlying assumptions are of relevance to current clinical practice in a number of areas. First, it suggests that, in the same way that seizure semiology is used in the context of epilepsy, the contents of hallucinations and illusions can be used as localising signs. By indicating increased activity in a specific functionally specialised cortical area, different types of visual hallucinations (eg, a face, colour or geometrical pattern) point to specific cortical locations, although not the location of the pathology causing the activity increase. Second, the classification highlights the fact that many symptoms held traditionally as distinct, appear closely related, if not indistinguishable, when considered from the perspective of their underlying mechanism. For example, synaesthesiae, functional hallucinations and reflex hallucinations are all likely to relate to the same underlying pathophysiology. Third, it predicts a number of theoretical disorders which are, as yet, undescribed, or at least not recognised as distinct clinical entities. For example, disorders classified here as hyperfunction of spatial coordinate frames within the parietal lobe (polyopia, visual perseveration, palinopsia, etc) do not have obvious deficit or disconnection counterparts. It is conceivable that their natural counterparts are, in fact, spatial neglect, simultanagnosia and oculomotor apraxia, classified here are as related to visual attention, as all are linked to the parietal lobe and dorsal stream. Finally, the classification highlights a number of areas which pose a challenge to visual neuroscience. For example, lilliputian hallucinations are not easily accommodated within current models of object perception, while polyopia and extracampine hallucinations are not easily accommodated within current models of spatial vision. In pointing to deficiencies in such models, visual perceptual disorders advance our understanding of normal visual function.

\section{CONCLUSIONS}

The last decade has seen advances in white-matter and functional imaging (including EEG imaging) that allow new classes of clinically relevant questions to be answered. ${ }^{79}$ We envisage that cutting-edge functional anatomical evidence derived from such techniques in single case and group studies, will be used to test and expand the classification presented here in the future. ${ }^{57}$ For now, we hope that our broad overview of visual perceptual disorders will provide a fresh perspective from which to challenge and refine the neuroscience of visual perception and visual perceptual dysfunction.

\section{Competing interests None.}

Provenance and peer review Commissioned; externally peer reviewed.

\section{REFERENCES}

1. Damasio AR. Disorders of complex visual processing agnosias, achromatopsia, Balint's syndrome, and related difficulties of orientation and construction. In: Mesulam MM, ed. Principles of Behavioural Neurology. Philadelphia: Davis 1985:259-88. 
2. Girkin CA, Miller NR. Central disorders of vision in humans. Surv Ophthalmol 2001;45:379-405

3. ffytche DH. Visual hallucinatory syndromes: past, present, and future. Dialogues Clin Neurosci 2007:9:173-89.

4. Blom JD. A Dictionary of Hallucinations. New York: Springer, 2010

5. Catani $\mathbf{M}$, ffytche $\mathrm{DH}$. The rises and falls of disconnection syndromes. Brain 2005; 128:2224-39.

6. von Monakow C. Diaschisis. (translated from 'Diaschisis' Die Lokalisation im Grosshirn und der abbau der Funktion durch korticale Herede, JF Bergmann, Wiesbaden, 1914). In: Pribram KH, ed. Brain and Behaviour 1: Mood States and Mind. Penguin, 1969:27-36.

7. ffytche DH. Visual hallucinations and the Charles Bonnet Syndrome. Curr Psychiatry Rep 2005; 7:168-79

8. ffytche DH. Neural codes for conscious vision. Trend Cognit Sci 2002;6:493-5.

9. Moutoussis $\mathbf{K}$, Zeki S. The relationship between cortical activation and perception investigated with invisible stimuli. Proc Natl Acad Sci U S A 2002;99:9527-32.

10. Catani M. Thiebaut de Schotten, Atlas of Human Brain Connections. Oxford: Oxford University Press, 2011

11. Zeki S, ffytche DH. The Riddoch syndrome: insights into the neurobiology of conscious vision. Brain 1998:121:25-45.

12. ffytche DH, Catani M. Beyond localization: from hodology to function. Philos Trans $R$ Soc Lond B Biol Sci 2005;360:767-79.

13. Catani M, Jones DK, Donato $\mathrm{R}$, et al. Occipito-temporal connections in the human brain. Brain 2003;126:2093-107.

14. Zeki S. A century of cerebral achromatopsia. Brain, 1990;113:1721-77.

15. Zeki S. Cerebral akinetopsia (visual motion blindness) - a review. Brain 1991;114:811-24

16. Zihl J, Von Cramon D, Mai N. Selective disturbance of movement vision after bilateral brain damage. Brain 1983;106:313-40.

17. Horton JC, Hoyt WF. Quadrantic visual field defects: a hallmark of lesions in extrastriate (V2N3) cortex. Brain 1991:114:1703-18.

18. Hadjikhani N, Sanchez Del Rio M, Wu O, et al. Mechanisms of migraine aura revealed by functional MRI in human visual cortex. Proc Natl Acad Sci U S A 2001:98:4687-92.

19. Fox CJ, laria G, Barton JJ. Disconnection in prosopagnosia and face processing. Cortex 2008;44:996-1009.

20. Landis T, Cummings JL, Benson DF, et al. Loss of topographic familiarity. An environmental agnosia. Arch Neurol 1986;43:132-6

21. Epstein R, Kanwisher N. A cortical representation of the local visual environment. Nature 1998;392:598-601.

22. Cohen L, Gray F, Meyrignac C, et al. Selective deficit of visual size perception: two cases of hemimicropsia. J Neurol Neurosurg Psychiatry 1994:57:73-8.

23. Ceriani F, Gentileschi V, Muggia S, et al. Seeing objects smaller than they are: micropsia following right temporo-parietal infarction. Cortex 1998;34:131-8.

24. Riddoch MJ, Humphreys GW. Visual agnosia. Neurol Clin 2003;21:501-20.

25. Wapner W, Judd T, Gardner H. Visual agnosia in an artist. Cortex 1978;14:343-64.

26. Martin PA. On scierneuropsia, a previously unnamed psychogenic visua disturbance. J Am Psychoanal Assoc 1960;8:71-81.

27. Mort DJ, Malhotra $P$, et al. The anatomy of visual neglect. Brain 2003:126:1986-97.

28. Thiebaut de Schotten M, Urbanski M, Duffau H, et al. Direct evidence for a parietal-frontal pathway subserving spatial awareness in humans. Science 2005:309:2226-8

29. Rizzo M, Robin DA. Simultanagnosia: a defect of sustained attention yields insights on visual information processing. Neurology 1990;40:447-55.

30. Michel F, Henaff MA. Seeing without the occipito-parietal cortex: simultagnosia as a shrinkage of the attentional visual field. Behav Neurol 2004;15:3-13.

31. Holliday IE, Kennard C, Ruddock KH. Rapid fading of visual sensations in a subject with a parietal-occipital tumour. Ophthalmic Physiol Opt 1985;5:149-56.

32. Adolphs R, Tranel D, Damasio $H$, et al. Impaired recognition of emotion in facial expressions following bilateral damage to the human amygdala. Nature 1994;372:669-72

33. Basso A, Bisiach E, Luzzatti C. Loss of mental imagery: a case study. Neuropsychologia 1980:18:435-42.

34. Hobson JA, Pace-Schott EF, Stickgold R. Dreaming and the brain: toward a cognitive neuroscience of conscious states. Behav Brain Sci 2000;23:793-842; discussion 904-1121.

35. Bischof M, Bassetti CL. Total dream loss: a distinct neuropsychological dysfunction after bilateral PCA stroke. Ann Neurol 2004;56:583-6.

36. ffytche DH. The hodology of hallucinations. Cortex 2008;44:1067-83.

37. Plant G. The fortification spectra of migraine. BMJ 1986;293:1613-17.

38. ffytche DH, Howard RJ, Brammer MJ, et al. The anatomy of conscious vision: an fMRI study of visual hallucinations. Nat Neurosci 1998;1:738-42.

39. Oertel V, Rotarska-Jagiela A, van de Ven VG, et al. Visual hallucinations in schizophrenia investigated with functional magnetic resonance imaging. Psychiatry Res Neuroimag 2007;156:269-73.

40. ffytche DH, Howard RJ. The perceptual consequences of visual loss: positive pathologies of vision. Brain 1999;122:1247-60.
41. ffytche DH, Lappin JM, Philpot M. Visual command hallucinations in a patient with pure alexia. J Neurol Neurosurg Psychiatry (Lond) 2004;75:80-6.

42. Heo K, Cho YJ, Lee SK, et al. Single-photon emission computed tomography in a patient with ictal metamorphopsia. Seizure 2004:13:250-3.

43. Critchley M. Types of visual perseveration: 'paliopsia' and 'illusory visual spread.' Brain 1951:74:267-99.

44. Santhouse AM, Howard RJ, ffytche DH. Visual hallucinatory syndromes and the anatomy of the visual brain. Brain 2000;123:2055-64.

45. Lopez JR, Adornato BT. Hoyt WF. 'Entomopia': a remarkable case of cerebral polyopia. Neurology 1993;43:2145.

46. Goldenberg G, Mullbacher W, Nowak A. Imagery without perception-a case study of anosognosia for cortical blindness. Neuropsychologia 1995;33:1373-82.

47. Brown R, Kulik J. Flashbulb memories. Cognition 1977;5:73-99

48. Gloor P, Olivier A, Quesney LF, et al. The role of the limbic system in experiential phenomena of temporal lobe epilepsy. Ann Neurol 1982:12:129-44.

49. Blanke 0, Landis T, Spinelli L, et al. Out-of-body experience and autoscopy of neurological origin. Brain 2004;127:243-58

50. Whiteside TC, Graybiel A, Niven Jl. Visual illusions of movement. Brain 1965;88:193-210.

51. Kolev 0I. Visual hallucinations evoked by caloric vestibular stimulation in norma humans. J Vestib Res 1995;5:19-23

52. Uchida H, Suzuki T, Tanaka KF, et al. Recurrent episodes of perceptual alteration in patients treated with antipsychotic agents. J Clin Psychopharmacol 2003:23:496-9.

53. Benke T. Peduncular hallucinosis: a syndrome of impaired reality monitoring. J Neurol 2006;253:1561-71.

54. Danta G, Hilton RC, O'Boyle DJ. Hemisphere function and binocular depth perception. Brain 1978;101:569-89.

55. Mitchell DE, Blakemore C. Binocular depth perception and the corpus callosum. Vision Res 1970;10:49-54.

56. Luzzatti C, Rumiati RI, Ghirardi G. A functional model of visuo-verbal disconnection and the neuroanatomical constraints of optic aphasia. Neurocase 1998:4:71-87.

57. Epelbaum S, Pinel P, Gaillard R, et al. Pure alexia as a disconnection syndrome: new diffusion imaging evidence for an old concept. Cortex 2008;44:962-74.

58. Coltheart M, Masterson J, Byng S, et al. Surface dyslexia. $0 \mathrm{~J}$ Exp Psychol A 1983:35:469-95.

59. Jackson SR, Newport $\mathrm{R}$, Husain $\mathrm{M}$, et al. There may be more to reaching than meets the eye: re-thinking optic ataxia. Neuropsychologia 2009:47:1397-408.

60. Ferro JM, Bravo-Marques JM, Castro-Caldas A, et al. Crossed optic ataxia: possible role of the dorsal splenium. J Neurol Neurosurg Psychiatry 1983:46:533-9.

61. Hartmann JA, Wolz WA, Roeltgen DP, et al. Denial of visual perception. Brain Cogn 1991:16:29-40.

62. Young AW, Hellawell DJ, Wright S, et al. Reduplication of visual stimuli. Behav Neurol 1994; 7:135-42

63. Ellis HD, Young AW. Accounting for delusional misidentifications. Br J Psychiatry 1990:157:239-48.

64. Sierra M, Lopera F, Lambert MV, et al. Separating depersonalisation and derealisation: the relevance of the 'lesion method.' J Neurol Neurosurg Psychiatry 2002:72:530-2.

65. Ross ED. Sensory-specific and fractional disorders of recent memory in man I. Isolated loss of visual recent memory. Arch Neurol 1980;37:193-200.

66. River Y, Ben Hur T, Steiner I. Reversal of vision metamorphopsia: clinical and anatomical characteristics. Arch Neurol 1998;55:1362-8.

67. von Cramon DY, Kerkhoff G. On the cerebral organization of elementary visuospatia perception. In: Gulyas B, Ottoson D, Roland P, eds. Functional Organisation of the Human Visual Cortex. Oxford: Pergamon Press, 1993:211-231.

68. Heilman KM, Watson RT. The disconnection apraxias. Cortex 2008:44:975-82

69. Lhermitte F. 'Utilization behaviour' and its relation to lesions of the frontal lobes. Brain 1983:106:237-55.

70. Hubl D, Koenig T, Strik W, et al. Pathways that make voices: white matter changes in auditory hallucinations. Arch Gen Psychiatry 2004;61:658-68.

71. Dixon MJ, Smilek D, Merikle PM. Not all synaesthetes are created equal: projector versus associator synaesthetes. Cogn Affect Behav Neurosci 2004;4:335-43.

72. Sagiv N, Simner J, Collins J, et al. What is the relationship between synaesthesia and visuo-spatial number forms? Cognition 2006;101:114-28.

73. Segal SJ, Gordon PE. The perky effect revisited: blocking of visual signals by imagery. Percept Mot Skills 1969;28:791-7.

74. Gray CR, Gummerman K. The enigmatic eidetic image: a critical examination of methods, data, and theories. Psychol Bull 1975;82:383-407.

75. Critchley M. The Parietal Lobes. New York: Hafner 1953.

76. Cummings JL, Gittinger JW Jr. Central dazzle. A thalamic syndrome? Arch Neurol 1981;38:372-4.

77. Good WV, Hou C. Sweep visual evoked potential grating acuity thresholds paradoxically improve in low-luminance conditions in children with cortical visual impairment. Invest Ophthalmol Vis Sci 2006;47:3220-4.

78. Rizzo M, Vecera SP. Psychoanatomical substrates of Balint's syndrome. J Neurol Neurosurg Psychiatry 2002;72:162-78.

79. Catani M, ffytche DH. On 'the study of the nervous system and behaviour.' Cortex 2010:46:106-9. 